\title{
High-density SNP arrays improve detection of HER2 amplification and polyploidy in breast tumors
}

Thomas v O Hansen ${ }^{1}$, Jonas Vikesaa ${ }^{1}$, Sine S Buhl ${ }^{1}$, Henrik H Rossing ${ }^{2}$, Vera Timmermans-Wielenga ${ }^{2}$ and Finn $C$ Nielsen $^{1 *}$

\begin{abstract}
Background: Human epidermal growth factor receptor-2 (HER2) overexpression and gene amplification are currently established by immunohistochemistry (IHC) and fluorescence in situ hybridization (FISH), respectively. This study investigates whether high-density single nucleotide polymorphism (SNP) arrays can provide additional diagnostic power to assess HER2 gene status.

Methods: DNA from 65 breast tumor samples previously diagnosed by HER2 IHC and FISH analysis were blinded and examined for HER2 copy number variation employing SNP array analysis.

Results: SNP array analysis identified 24 (37\%) samples with selective amplification or imbalance of the HER2 region in the q-arm of chromosome 17. In contrast, only 15 (23\%) tumors were found to have HER2 amplification by IHC and FISH analysis. In total, there was a discrepancy in 19 (29\%) samples between SNP array and IHC/FISH analysis. In 12 of these cases, the discrepancy towards FISH could be attributed to concomitant amplification or deletion of the centromeric region, which harbors the FISH reference probe sequence. In 3 tumors, repeated IHC/FISH analysis revealed that the original IHC/FISH analysis had failed to indicate the correct HER2 expression level. Finally, the SNP array analysis revealed that more than two thirds of the samples exhibited polyploidy that was unrecognized by conventional FISH.

Conclusions: Collectively, the data show that determination of HER2 copy number variations by SNP array-based genomic segmentation analysis is an effective supplement to IHC/FISH HER2 analysis that, by providing additional diagnostic sensitivity and accuracy, may elect more women for targeted treatment with HER2 inhibitors.
\end{abstract}

Keywords: Breast cancer, HER2 amplification, Polyploidy, SNP array

\section{Background}

Breast cancer is the most common type of cancer among women and approximately 430,000 new cases are diagnosed every year in Europe [1]. Breast cancer development and progression rely on several molecular pathways including estrogen receptor and human epidermal growth factor receptor-2 (HER2) receptor signaling, which represent important prognostic indicators and provide the molecular basis for targeted treatment by antibodies or small molecule inhibitors.

\footnotetext{
*Correspondence: fcn@rh.dk

'Center for Genomic Medicine, Copenhagen University Hospital, Blegdamsvej 9 , DK-2100 Copenhagen, Denmark

Full list of author information is available at the end of the article
}

HER2 is located on chromosome 17q12 and the gene is amplified in approximately $15-25 \%$ of breast cancers $[2,3]$. The HER/EGFR family of tyrosine kinases activates several mitogenic signaling pathways, such as the MAPK, PI3K/Akt, and mTOR pathways [4], and gene amplification is associated with a more aggressive course and reduced expression of estrogen and progesterone receptors $[3,5,6]$. On the other hand, antibodies or small molecule inhibitors such as Trastuzumab and Lapatinib efficiently inhibit the HER2 receptor and have been shown to improve overall survival and reduce risk of relapse [7-11]. Consequently, accurate testing of HER2 amplification is of major importance for clinical decision-making in breast cancer patients.

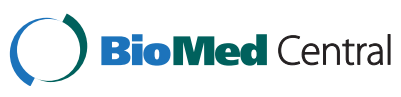

(C) 2015 Hansen et al.; licensee BioMed Central. This is an Open Access article distributed under the terms of the Creative Commons Attribution License (http://creativecommons.org/licenses/by/2.0), which permits unrestricted use, distribution, and reproduction in any medium, provided the original work is properly credited. The Creative Commons Public Domain Dedication waiver (http://creativecommons.org/publicdomain/zero/1.0/) applies to the data made available in this article, unless otherwise stated. 
HER2 overexpression and gene amplification are normally established by a combination of immunohistochemistry (IHC) and fluorescence in situ hybridization (FISH). These procedures have been evaluated in a number of studies [12-19] and this has revealed that up to $20 \%$ of HER2 testing results may be inaccurate [20]. Moreover, external quality assurance tests have indicated that due to the subjective nature of the IHC scoring system, fixation procedures, and histopathological assessments, only $75 \%$ of the participating laboratories consistently provided reproducible results [21,22]. As a result, a number of women are prevented from receiving the most effective treatment, while others are pointlessly treated with costly medicine with potentially harmful side effects [23]. As an illustration of the problem, it has been highlighted that a number of patients treated with Trastuzumab responded well $[24,25]$ despite the fact that they tested negative for HER2 amplification [26]. Finally, HER2 FISH analysis has difficulties in identifying polysomy of chromosome 17 [27], which may complicate the interpretation of HER2 testing results [28].

Thus, alternative methods are warranted to improve the accuracy of HER2 analysis. Determination of copy number variations (CNVs) by high-density single nucleotide polymorphism (SNP) arrays is an appealing possibility because the technology provides an unbiased and highly reproducible measure of gene copy numbers. Furthermore, the analysis provides information about the entire genome, making it feasible to obtain data from other genes of interest, such as TOP2A, as they become validated for breast cancer diagnosis. In the present study, we assessed the HER2 status of 65 breast tumors by high-density SNP array analysis and compared the results with those previously determined by IHC and FISH. Our data show that SNP arrays provide additional diagnostic sensitivity and accuracy compared to IHC and FISH analysis that appears to underestimate the number of cancers with HER2 amplification. Therefore, SNP arrays could be a valuable supplement for analysis of HER2 amplification by assigning more women with breast cancer to targeted treatment.

\section{Methods}

\section{Patient samples}

Breast cancer samples were routinely processed according to national guidelines. The original stainings and hybridizations were part of the routine clinical workload of the Department of Pathology, while SNP arrays were part of the routine analysis repertoire at the Center of Genomic Medicine. Therefore the scientific ethics committee of the Capital Region of Denmark determined that no ethical approval was necessary (H-3-2013FSP55). The research was carried out in compliance with the Helsinki Declaration. Sixty-five breast cancer samples were collected between 2008 and 2009. The tumor samples were randomly selected comprising the following five categories: (1) IHC 0; (2) IHC 1+; (3) IHC $2+$, not amplified by FISH; (4) IHC 2+, amplified by FISH; and (5) IHC 3+. The study aimed to contain 50\% HER 2+ tumor samples.

\section{Immunohistochemistry (IHC)}

Fresh breast tumor tissue was immediately placed in formalin fixative and paraffin embedded. Six-micrometer sections were cut from the tissue blocks and mounted on Super Frost Plus slides (Menzel-Gläser). HER2 status was assessed using the HercepTest ${ }^{\mathrm{TM}}$ kit K5207 (Dako) and HercepTest ${ }^{\mathrm{Tm}}$ Autostainer plus link (Dako) following the manufacturer's recommendations. Processed immunohistochemical slides were scored according to the recommendations of the American Society of Clinical Oncology/College of American Pathologists [20]. Each case was categorized as $0,1+, 2+$ or $3+$ and specimens scoring $3+$ were considered as HER2 positive. Cases scoring $2+$ were regarded as equivocal and were subsequently assessed by HER2 FISH analysis. Cases scored as 0 or $1+$ were considered as HER 2 negative. All original stainings were part of the routine clinical workload of the Department of Pathology and the results were acquired from the clinical records and therefore represent the actual readings of different pathologists. The analysis is subjected to both internal and external control (UK NEQAS).

\section{Fluorescence in situ hybridization (FISH)}

FISH was performed on all cases scoring 2+ on HercepTest ${ }^{\mathrm{Tm}}$ and for quality control purposes on a proportion of the divergent cases from the study group. Sections of 2-4- $\mu \mathrm{m}$ thickness were cut from paraffin blocks, mounted on Super Frost Plus slides and baked for $60 \mathrm{~min}$ at $60^{\circ} \mathrm{C}$. HER2 status was assessed using the HER2 FISH pharmDx ${ }^{\mathrm{TM}}$ kit K5331 (Dako). The HER2 probes were labeled with Tx-Red and the control probe mix targeting the centromere on chromosome 17 (CEP17) was labeled with FITC. The level of HER2 gene amplification was determined in the tissue sections by counting the green and red signals in the nuclei of a minimum of 20 invasive carcinoma cells. The amplification ratio is the ratio of red to green signals in each section, using a cut-off point of 2 . Cases with a ratio of 2 or more were regarded to have amplification of the HER2 gene. All original hybridizations were part of the routine clinical workload of the Department of Pathology and the results were acquired from the clinical records and therefore represent the actual readings of different pathologists. The analysis is subjected to both internal and external control (UK NEQAS). 
In order to assess FISH staining per nucleus, the standard protocol was modified as follows. Paraffin section thickness was increased to 10-12 $\mu \mathrm{m}$. Labeling was performed as described above, except TO-PRO3 (Invitrogen) was applied as a nuclear marker. Sections were examined on a Zeiss LSM 510 Confocal Microscope, using a $100 \times$ objective and a multitrack triple color setting. Consecutive confocal images were taken with a thickness of $0.39 \mu \mathrm{m}$. Three-dimensional models were generated from the Z-stack sections using the Zeiss Image browser software. A minimum of two Zstacks containing $>30$ cells were generated per sample. The results are stated as the observed average of HER2 copies per nucleus.

\section{DNA purification}

DNA was purified from snap-frozen breast cancer samples macrodissected by a pathologist. The samples were incubated at $55^{\circ} \mathrm{C}$ overnight in $200 \mu \mathrm{l}$ TNES buffer (10 mM Tris- $\mathrm{HCl}(\mathrm{pH} 7.5), 400 \mathrm{mM} \mathrm{NaCl}, 100 \mathrm{mM}$ EDTA, $0.6 \% \mathrm{SDS})$ and $20 \mu \mathrm{l}$ Proteinase $\mathrm{K}(20 \mathrm{mg} / \mathrm{ml})$. Genomic DNA was isolated using $\mathrm{NaCl}$ precipitation, washed with $70 \%$ ethanol, dried and resuspended in Tris-EDTA buffer. The DNA integrity was examined by agarose gel analysis and the DNA concentration was determined using the NanoDrop ND-1000 spectrophotometer (NanoDrop Technologies).

\section{SNP array analysis}

Forty-seven DNA samples were analyzed using Affymetrix SNP $500 \mathrm{~K}$ arrays and 18 DNA samples were analyzed using the SNP 6.0 array according to Affymetrix's instructions. CEL files were analyzed with Partek Genomics Suite 6.5. Data were imported using the default Partek settings, including adjustments for probe sequence, background and quantile normalization, and allele-specific summarizing of probes. Copy number state and SNP allele ratio were calculated by an unpaired analysis using a baseline generated from 76 healthy Danish controls in the case of the SNP $500 \mathrm{~K}$, and 270 samples from the international HapMap project for the SNP 6.0 arrays. The average value of all copy number probe intensity calls across the genome was assigned as copy number state 2 . Segmentation analysis was performed on copy number probe intensity calls using Partek's genomic segmentation algorithm, which determines breakpoints in the data rather than calculating a predefined copy number state. The algorithm determines a segment using the following criteria: (1) neighboring regions have statistically different average intensities $(\mathrm{p}<0.001),(2)$ breakpoints are chosen to give the best statistical significance (smallest p-value), (3) detected regions must contain a minimum number of data points (SNP $500 \mathrm{~K}=100$, SNP $6.0=200$ ), and (4) the minimum magnitude of changes to be detected relative to the noise estimate for each chromosome is set to 0.3. The detected segments were analyzed in order to determine their copy number status (normal, deletion or amplification). The copy number range was set to 0.2 and the p-value threshold to 0.01 , so $<1.8=$ deletion, $1.8<x<2.2=$ normal, $>2.2=$ amplification. In order to verify that our genomic segmentation model parameters did indeed call actual strand breaks, we conducted a visual inspection of predicted strand breaks verifying a change in allele ratio. This showed that the $1.8<x<2.2$ segmentation model provides a conservative estimate with no falsepositive strand breaks.

To determine the extent of polyploidy in the tumor samples, the different copy number fragment states in combination with the allelic balances at all chromosomes was examined. A tumor was assigned as polyploid if the median intensity probes throughout all chromosomes were concluded to be 3 copies or more. It was not always possible to determine the precise number of the polyploid state, and in these cases only the lowest possible estimate is indicated.

\section{Results}

Pathological characteristics of the breast tumor samples

Sixty-five primary breast tumor samples were selected for the study, comprising 12 tumors scored as IHC 0, 15 as IHC $1+, 32$ as IHC $2+$, and 6 as IHC $3+$ (Table 1, HER2 IHC). The HER2/CEP17 ratios of all the IHC 2+ tumor samples were examined by FISH analysis (Table 1 , HER2 FISH). Nine of the IHC 2+ tumors had a HER2/ CEP17 ratio of more than 2.0, 18 IHC 2+ tumor samples had a HER2/CEP17 ratio between 1.5 and 2.0, while the remaining 5 IHC $2+$ tumor samples had a HER2/CEP17 ratio below 1.5. In total, 15 (23\%) tumor samples were found to have HER2 amplification by IHC and FISH analysis. Other pathological data is shown in Additional file 1.

\section{SNP array copy number analysis}

Sixty-five frozen tumors were initially examined by SNP $500 \mathrm{~K}$ or SNP 6.0 arrays in a blinded manner. To examine the reproducibility of the SNP assay, 10 tumor samples were initially replicated on newly isolated DNA using SNP $500 \mathrm{~K}$. All the replicated samples exhibited identical results. Moreover, CNVs detected by the separ-

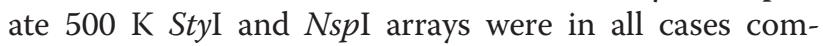
pletely overlapping, inferring that the technical variation in the array-based detection of CNVs was negligible.

Copy number variations and breakpoints were depicted and the compiled results of all chromosomes from all tumor samples are shown in Additional file 2. The tumors exhibited a large number of different CNVs 
Table 1 Comparison of IHC, FISH and SNP data

\begin{tabular}{|c|c|c|c|c|c|}
\hline \multirow[b]{2}{*}{$\begin{array}{l}\text { Tumor } \\
\text { sample } \\
\text { number }\end{array}$} & \multicolumn{2}{|c|}{ IHC/FISH } & \multicolumn{3}{|l|}{ SNP array } \\
\hline & $\begin{array}{l}\text { HER2 } \\
\text { IHC }\end{array}$ & HER2 FISH & $\begin{array}{l}\text { HER2 } \\
\text { segment } \\
\text { copy } \\
\text { number }\end{array}$ & $\begin{array}{l}\text { HER2/CEP17 } \\
\text { ratio }\end{array}$ & $\begin{array}{l}\text { HER2 copy } \\
\text { number } \\
\text { status }\end{array}$ \\
\hline 1 & 0 & $\mathrm{n} / \mathrm{a}$ & 1,98 & balance & normal \\
\hline 2 & 0 & $\mathrm{n} / \mathrm{a}$ & 2,35 & HER2+ & $a m p^{*}$ \\
\hline 3 & 0 & 1,92 & 1,81 & balance & normal \\
\hline 4 & 0 & $\mathrm{n} / \mathrm{a}$ & 2,06 & balance & normal \\
\hline 5 & 0 & $\mathrm{n} / \mathrm{a}$ & 2,04 & balance & normal \\
\hline 6 & 0 & $\mathrm{n} / \mathrm{a}$ & 1,72 & cent+ & del \\
\hline 7 & 0 & $\mathrm{n} / \mathrm{a}$ & 1,67 & balance & del \\
\hline 8 & 0 & $\mathrm{n} / \mathrm{a}$ & 1,83 & balance & normal \\
\hline 9 & 0 & $\mathrm{n} / \mathrm{a}$ & 1,51 & cent+ & del \\
\hline 10 & 0 & $\mathrm{n} / \mathrm{a}$ & 2,51 & balance & $a m p *$ \\
\hline 11 & 0 & $\mathrm{n} / \mathrm{a}$ & 1,78 & balance & del \\
\hline 12 & 0 & $\mathrm{n} / \mathrm{a}$ & 1,85 & balance & normal \\
\hline 13 & 1 & $\mathrm{n} / \mathrm{a}$ & 1,97 & balance & normal \\
\hline 14 & 1 & $\mathrm{n} / \mathrm{a}$ & 2,08 & balance & normal \\
\hline 15 & 1 & 0,83 & 2,33 & balance & $a m p^{*}$ \\
\hline 16 & 1 & 0,80 & 1,70 & balance & del \\
\hline 17 & 1 & 0,80 & 1,80 & cent+ & normal \\
\hline 18 & 1 & 0,86 & 2,49 & balance & $a m p^{*}$ \\
\hline 19 & 1 & $\mathrm{n} / \mathrm{a}$ & 2,06 & balance & normal \\
\hline 20 & 1 & $\mathrm{n} / \mathrm{a}$ & 2,09 & balance & normal \\
\hline 21 & 1 & $\mathrm{n} / \mathrm{a}$ & 1,96 & balance & normal \\
\hline 22 & 1 & $\mathrm{n} / \mathrm{a}$ & 1,97 & balance & normal \\
\hline 23 & 1 & $\mathrm{n} / \mathrm{a}$ & 2,13 & balance & normal \\
\hline 24 & 1 & $\mathrm{n} / \mathrm{a}$ & 1,90 & balance & normal \\
\hline 25 & 1 & $\mathrm{n} / \mathrm{a}$ & 1,87 & balance & normal \\
\hline 26 & 1 & $\mathrm{n} / \mathrm{a}$ & 4,46 & balance & $a m p^{*}$ \\
\hline 27 & 1 & $\mathrm{n} / \mathrm{a}$ & 2,34 & balance & $a m p^{*}$ \\
\hline 28 & 2 & 1,41 & 2,45 & balance & $a m p^{*}$ \\
\hline 29 & 2 & 1,54 & 2,16 & balance & normal \\
\hline 30 & 2 & $3,05^{*}$ & 2,04 & balance & normal \\
\hline 31 & 2 & $2,69^{*}$ & 2,48 & balance & $a m p *$ \\
\hline 32 & 2 & $2,42^{*}$ & 1,75 & cent+ & del \\
\hline 33 & 2 & 1,73 & 1,99 & balance & normal \\
\hline 34 & 2 & $2,65^{*}$ & 1,92 & balance & normal \\
\hline 35 & 2 & 1,50 & 1,91 & balance & normal \\
\hline 36 & 2 & 1,57 & 2,00 & balance & normal \\
\hline 37 & 2 & 1,68 & 1,79 & balance & del \\
\hline 38 & 2 & 1,90 & 1,84 & balance & normal \\
\hline 39 & 2 & 1,60 & 2,05 & balance & normal \\
\hline 40 & 2 & 1,58 & 1,89 & balance & normal \\
\hline 41 & 2 & $2,13^{*}$ & 2,73 & balance & amp* \\
\hline
\end{tabular}

Table 1 Comparison of IHC, FISH and SNP data (Continued)

\begin{tabular}{|c|c|c|c|c|c|}
\hline 42 & 2 & 1,54 & 2,04 & balance & normal \\
\hline 43 & 2 & 1,82 & 1,54 & balance & del \\
\hline 44 & 2 & 1,90 & 1,77 & balance & del \\
\hline 45 & 2 & 1,66 & 2,33 & balance & amp* \\
\hline 46 & 2 & 1,48 & 2,04 & balance & normal \\
\hline 47 & 2 & 1,73 & 1,98 & balance & normal \\
\hline 48 & 2 & 1,67 & 2,36 & balance & $a m p *$ \\
\hline 49 & $2 / 3$ & $0,93 / 8,8$ & 11,10 & HER2+ & $a m p^{*}$ \\
\hline 50 & 2 & 1,81 & 2,04 & balance & normal \\
\hline 51 & 2 & 1,58 & 2,65 & HER2+ & $a m p *$ \\
\hline 52 & 2 & 1,60 & 2,23 & balance & $a m p^{*}$ \\
\hline 53 & 2 & $2,27^{*}$ & 8,03 & HER2+ & $a m p^{*}$ \\
\hline 54 & 2 & 1,87 & 2,91 & balance & $a m p^{*}$ \\
\hline 55 & 2 & 1,24 & 2,66 & balance & $a m p^{*}$ \\
\hline 56 & 2 & $7,38^{*}$ & 7,01 & HER2+ & $a m p *$ \\
\hline 57 & 2 & 1,00 & 1,88 & balance & normal \\
\hline 58 & 2 & $8,60^{*}$ & 7,98 & HER2+ & $a m p^{*}$ \\
\hline 59 & 2 & $3,24^{*}$ & 3,18 & HER2+ & $a m p^{*}$ \\
\hline 60 & $3 * / 1$ & 1,65 & 2,00 & balance & normal \\
\hline 61 & 3 & $4,11^{*}$ & 5,28 & HER2+ & $a m p^{*}$ \\
\hline 62 & 3 & $7,00^{*}$ & 4,58 & HER2+ & $a m p *$ \\
\hline 63 & $3 * / 2$ & 1,50 & 2,05 & balance & normal \\
\hline 64 & $3^{*}$ & $\mathrm{n} / \mathrm{a}$ & 3,15 & HER2+ & $a m p^{*}$ \\
\hline 65 & $3^{*}$ & 1,35 & 3,75 & HER2+ & $a m p^{*}$ \\
\hline
\end{tabular}

Asterisk indicates HER2 positive results, while bold indicates samples that have been reanalyzed. Abbreviations: amp amplified CEP17 centromere on chromosome 17, del deletion, FISH fluorescent in situ hybridization, HER2 human epidermal growth factor receptor-2, IHC immunohistochemistry, n/a not analysed.

across the whole genome, in agreement with previous results $[29,30]$.

According to the genomic segmentation analysis, 24 (37\%) tumor samples exhibited selective amplification of the HER2 region, whereas 9 had HER2 deletion and 32 exhibited normal HER2 status (Table 1, HER2 copy number status). Four-fold or greater amplification (4.4611.10-fold) of HER2 was observed in 7 samples (tumor sample $26,49,53,56,58,61$, and 62 ), whereas 17 samples (tumor sample 2, 10, 15, 18, 27, 28, 31, 41, 45, 48, $51,52,54,55,59,64$, and 65$)$ had a more moderate HER2 amplification (2.23-3.75-fold). The minimal amplified region surrounding HER2 according to the genomic segmentation algorithm covered $\sim 328 \mathrm{~kb}$ DNA (Figure 1), while the largest amplified region consisted of a complete duplication of chromosome 17 (in two cases). The minimal region contained 11 genes that - in addition to HER2 - comprised partial CDK12, NEUROD2, PPP1R1B, STARD3, TCAD, PNMT, PGAP3, c17orf37, GRB7, partial IKZF3. 


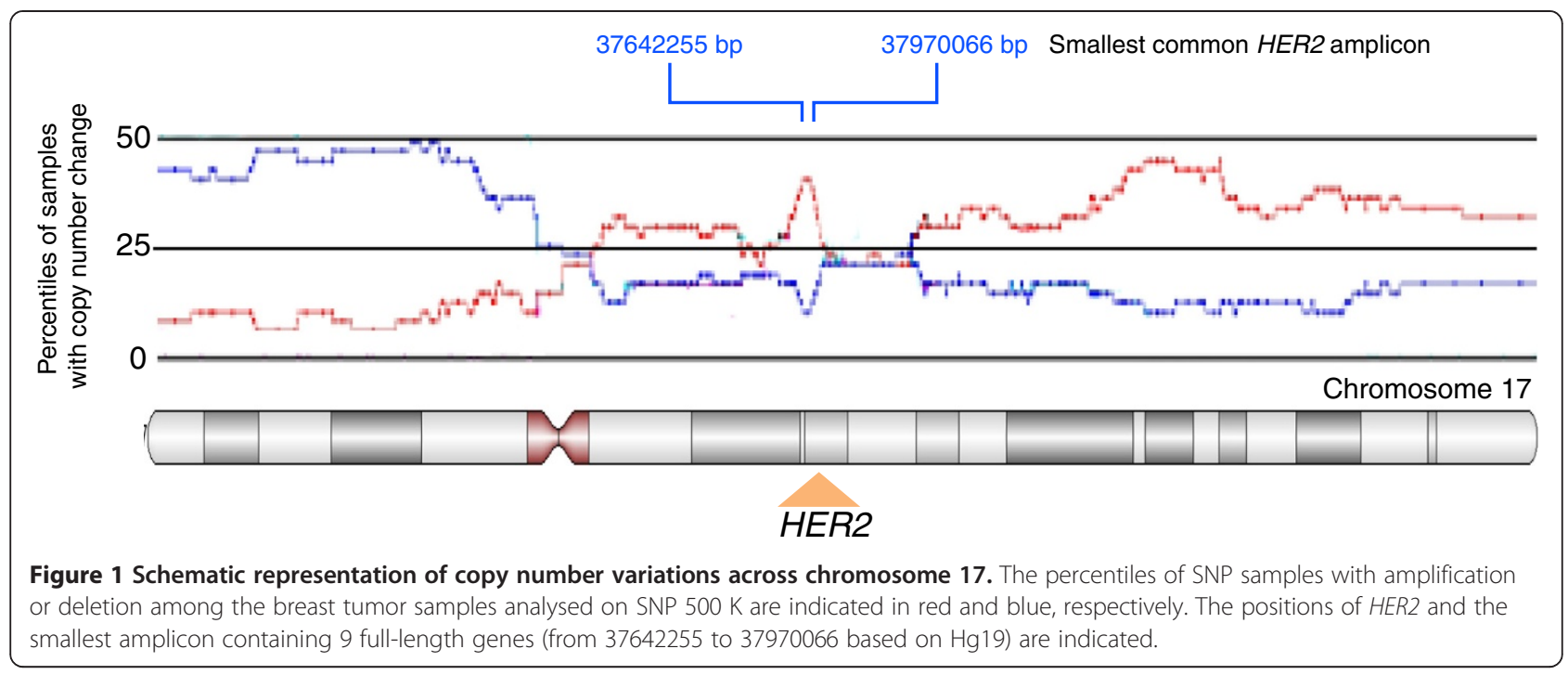

\section{Comparison of SNP array data with IHC and FISH}

In 46 (71\%) tumor samples, the HER2 status was confirmed by SNP array analysis (Table 1). In 19 (29\%) tumor samples, however, there was a discrepancy between the SNP analysis and IHC/FISH, including 2/12 (16.7\%) of the IHC 0 samples, 4/15 (26.7\%) of the IHC 1 + samples, $11 / 32(34.4 \%)$ of the IHC $2+$ samples, and $2 / 6(33.3 \%)$ of the IHC $3+$ samples. Altogether, the 19 samples comprised 14 IHC/FISH-negative and $5 \mathrm{IHC} /$ FISH-positive HER2 results. According to the SNP array data, 11 of the IHC/FISH-negative samples (tumor sample $10,15,18,26,27,28,45,48,52,54$, and 55) exhibited HER2 amplification without any change in the HER2/CEP17 ratio. Tumor sample 26 is shown in Figure 2 as an example. One sample (tumor sample 49) was reanalyzed by $\mathrm{IHC} / \mathrm{FISH}$, and this analysis revised the classification, previously scored as IHC 2+ with a HER2/CEP17 ratio of 0.93 , to IHC $3+$ with a HER2/ CEP17 ratio of 8.8 (Table 1). The last 2 IHC/FISH-negative samples were scored as IHC 0 (tumor sample 2) and IHC 2+ (tumor sample 51) with a HER2/CEP17 ratio of 1.58 . Both tumor samples had a moderate but visible HER2 amplification when analyzed by SNP array (Table 1). Among the IHC/FISH-positive HER2 samples, 2 were IHC $3+$ cases (tumor sample 60 and 63). These 2 cases were reanalyzed by IHC and FISH, and were subsequently reclassified as IHC $1+$ and IHC 2+, respectively, with a HER2/CEP17 ratio of 1.65 and 1.5, respectively. The 3 other IHC/FISH-positive samples were all scored as IHC 2+ (tumor sample 30, 32, and 34 ) with a HER2/CEP17 ratio of $3.05,2.42$, and 2.65 , respectively. In these cases, the SNP array data classified the tumor samples as normal (tumor sample 30 and 34) or with HER2 deletion (tumor sample 32).

\section{Polyploidy}

During the analysis of the SNP array data, it became evident that the baseline 2 value was incorrectly mapped in a number of samples because the SNP probes indicated imbalance despite the fact that copy numbers were centered around 2. By combining the information of copy number fragment states and allelic balances, it was possible to establish that the samples were in fact polyploid (defined as having more than 2 sets of all chromosomes). As an example, tumor sample 5 (Figure 3) did not exhibit any local CNVs in chromosome 17 . However, on chromosome 14, it could be deducted that the assigned copy number state 2 intensity value corresponded to 4 DNA copies (for detailed information, please refer to the figure legend). Additional file 3 shows an additional case of polyploidy in tumor sample 45 . In total, 45 (69\%) of the tumor samples were found to have undergone global duplication of their entire genome (Table 2). The polyploid status was correlated to HER2 copy number (Table 2, HER2 copy number estimate). To verify the calling of polyploidy, we modified the HER2 FISH protocol and increased the section thickness to $10-12 \mu \mathrm{m}$ in order to encompass a whole nucleus. The sections were examined by confocal microscopy with high magnification and Z-stack imaging generated 3D-rendered reconstructions of the entire nucleus. Nine samples that were assigned as being polyploid were examined. Since cells in late $\mathrm{S}$ or $\mathrm{G} 2$ phase will display double the amount of HER2 and CEP17 probe signals, these cells were excluded from the analysis. The number of HER2 gene copies (red dots) observed per nucleus/tumor cell is listed in Table 2 (HER2 copy number per nucleus (3D FISH)). In all nine cases, the analysis confirmed that the tumor samples were polyploid. Representative images of 

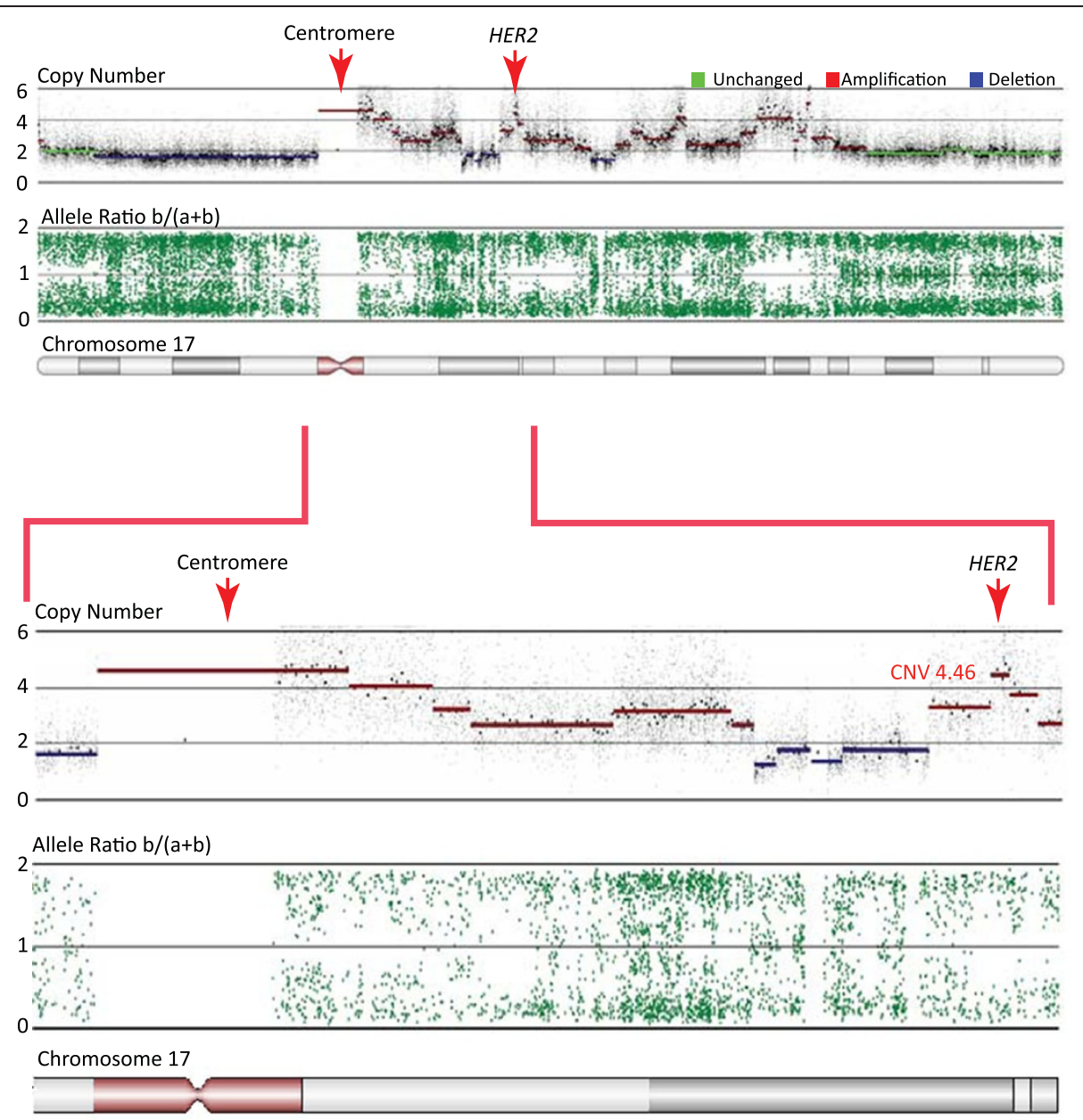

Figure 2 Co-amplification of chromosome 17 centromere and HER2. SNP data from tumor sample 26 displaying the copy number and allele ratios across chromosome 17. This sample has undergone multiple DNA breaks and several regions of the chromosome $17 \mathrm{q}$ arm are amplified, including a region around HER2 (4.46-fold) and a region close to the centromere. The two regions are amplified to the same extent and may therefore explain the negative IHC HER2/CEP17 even though the HER2 gene is clearly amplified.

the 3D renderings are shown in Figure $3 \mathrm{C}$ and Additional file 3 . In both cases, more than 2 copies of both HER2 and CEP17 were found to exist. Moreover, in all nine tumor samples, the observed number of copies of HER2 (red signal) and CEP17 (green signal) was found to be in accordance with the estimated copy number based on SNP array calculations alone. This finding was confirmed using probes recognizing the centromere of chromosome 7 (CEP7) and chromosome 17 (CEP17), respectively (data not shown).

\section{Discussion}

According to the guidelines of the American Society of Clinical Oncology (ASCO)/College of American Pathologists (CAP), HER2 overexpression and gene amplification should be established by a combination of IHC and FISH. Recent reports indicate, however, that about 20\% of $H E R 2$ testing results may be incorrect [20]. Moreover, in a group of HER2 IHC 0 tumor samples, it has been reported that FISH identified positive HER2 amplification in $2-8 \%$ of the cases, while $5-22 \%$ of HER2 IHC $3+$ tumor samples were found to lack HER2 amplification according to FISH (reviewed in [31]). Since the correct measurement of HER2 copy numbers is essential for instigation of targeted therapy [32,33], we investigated whether it is possible to improve the accuracy of the analysis by employing high-density SNP arrays.

SNP arrays were developed for global analysis of single nucleotide polymorphisms, but by adding information about the intensity of particular SNPs, the analysis may be exploited to identify CNVs with high sensitivity, resolution, and reproducibility [34,35]. Current high-density SNP arrays detect CNVs in the range of about 5-10 kb. Considering that the HER2 amplicon covers at least $280 \mathrm{~kb}$ DNA [36,37], the resolution of SNP-based CNV detection is more than sufficient to provide detailed 
A

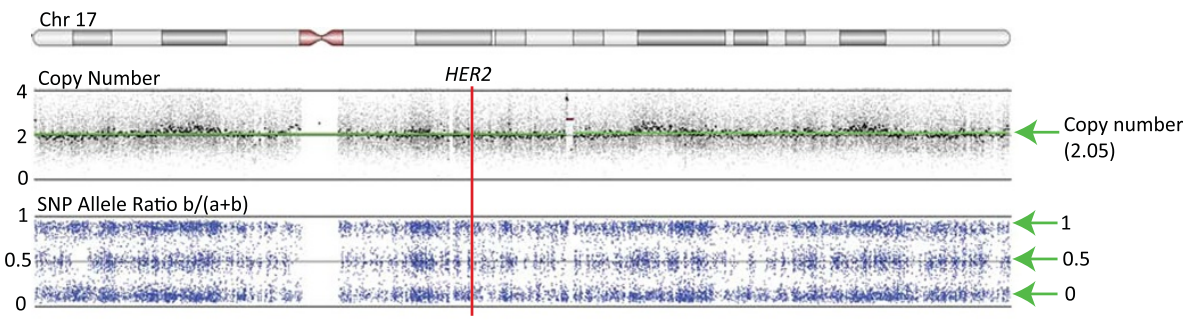

B

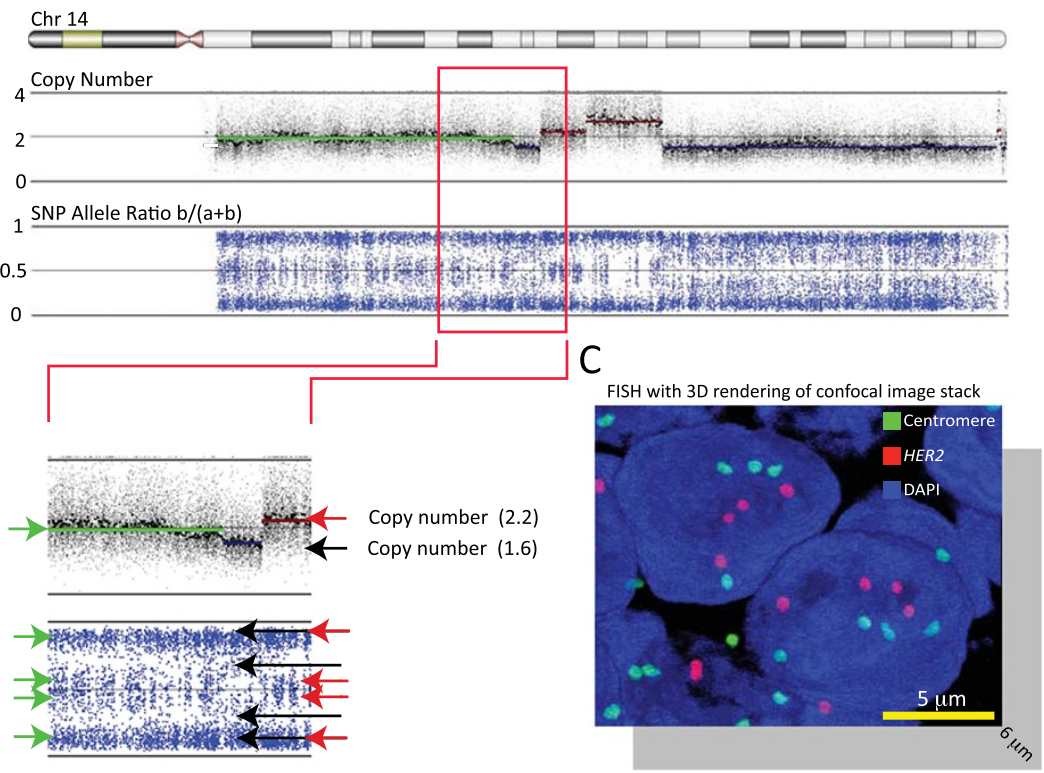

Figure 3 Detection of polyploidy. (A) SNP and copy number data across chromosome 17 from tumor sample 5. The top panel displays the copy number probe intensity calls and the calculated copy number segments (in color). The calculated segment (green line) has an intensity value of just over 2. The lower panel displays the calculated SNP allele ratios and shows that the entire chromosome 17 is in allelic balance. The vertical red line indicates the position of HER2. (B) SNP and copy number data across chromosome 14 from tumor sample 5. The enlargement of the red box shows that a segment (green line) is predicted with an intensity value of just under 2. However, a weak allelic imbalance (green arrows) suggests that the intensity value of just under 2 does not correspond to 2 DNA copies. Moreover, a deletion ( 1.6) and an amplification ( 2.2) only result in a modest copy number intensity change. Taken together, the data in (A) and (B) suggest that a segment with an intensity value of just over 2 and allelic balance must correspond to at least 4 copies of DNA. (C) Representative image of a 3D-rendered model of a confocal image stack of a section from tumor sample 5 hybridized with HER2 (red) and CEP17 (green) probes. The image extends $6 \mu \mathrm{m}$ down into the z-axis, corresponding to $\sim 60-70 \%$ of the nucleus diameter.

information about the amplicon. Moreover SNP arrays are able to detect alterations in samples containing down to $10 \%$ tumor tissue [38].

Several different algorithms based on simple defined thresholds to complex statistical modeling have been developed to call CNVs. We employed a genomic segmentation algorithm which defines breakpoints based on systematic change in intensity along the chromosome, unlike the Hidden Markov Model which allocates intensities to a predefined copy number state $(0,1,2,3 \ldots \ldots)$. In this way, the segmentation algorithm allows the identification of CNVs that are less than a whole copy number state. We considered this to be important for clinical use because factors such as contamination by normal tissue, tumor heterogeneity, and polyploidy in the tumor may lead to fractional copy number changes.

The discrepancy between SNP arrays and FISH can be mainly explained by the fact that 12 amplicons included the centromeric region of chromosome 17 that harbors the binding site of the CEP17 reference probe. CEP17 may therefore not be the optimal reference probe and other centromere probes, e.g. on chromosome 2 or 9 , which comprise few rearrangements in breast tumors are recommended (Additional file 2). In 3 samples, revision of the IHC/FISH analysis showed that they were in fact in agreement with the SNP data. Taken together, the results indicate that SNP arrays increase the sensitivity and specificity of the HER2 analysis. 
Table 2 Summary of polyploidy

\begin{tabular}{|c|c|c|c|}
\hline $\begin{array}{l}\text { Sample } \\
\text { number }\end{array}$ & Polyploidy & $\begin{array}{l}\text { HER2 copy number } \\
\text { estimate }\end{array}$ & $\begin{array}{l}\text { HER2 copy number } \\
\text { per nucleus (3D FISH) }\end{array}$ \\
\hline 1 & No & normal & \\
\hline 2 & Yes & $5+$ & \\
\hline 3 & Yes & $3+$ & \\
\hline 4 & No & normal & \\
\hline 5 & Yes & $4+$ & $4-5$ \\
\hline 6 & Yes & $3+$ & \\
\hline 7 & Yes & $3+$ & \\
\hline 8 & Yes & $4+$ & \\
\hline 9 & Yes & $3+$ & \\
\hline 10 & No & 3 & \\
\hline 11 & Yes & $3+$ & \\
\hline 12 & Yes & $5+$ & \\
\hline 13 & No & normal & \\
\hline 14 & No & normal & \\
\hline 15 & Yes & $5+$ & \\
\hline 16 & Yes & $3+$ & \\
\hline 17 & Yes & $3+$ & \\
\hline 18 & No & $3+$ & \\
\hline 19 & No & normal & \\
\hline 20 & No & normal & \\
\hline 21 & Yes & $5+$ & \\
\hline 22 & Yes & 4 & \\
\hline 23 & Yes & $4+$ & \\
\hline 24 & Yes & $3+$ & \\
\hline 25 & No & normal & \\
\hline 26 & Yes & $6+$ & \\
\hline 27 & Yes & $4+$ & $5-7$ \\
\hline 28 & Yes & $4+$ & \\
\hline 29 & Yes & $4+$ & $4-6$ \\
\hline 30 & Yes & $5+$ & \\
\hline 31 & Yes & $5+$ & $5-7$ \\
\hline 32 & Yes & $3+$ & \\
\hline 33 & No & normal & \\
\hline 34 & Yes & $5+$ & $5-7$ \\
\hline 35 & No & normal & \\
\hline 36 & Yes & $5+$ & $4-5$ \\
\hline 37 & Yes & $3+$ & \\
\hline 38 & Yes & $3+$ & \\
\hline 39 & No & normal & \\
\hline 40 & No & normal & \\
\hline 41 & Yes & $5+$ & \\
\hline 42 & No & normal & \\
\hline 43 & Yes & UPD(2) or amp3 & 2 \\
\hline
\end{tabular}

Table 2 Summary of polyploidy (Continued)

\begin{tabular}{|c|c|c|c|}
\hline 44 & Yes & $5+$ & \\
\hline 45 & Yes & $8+$ & 8 \\
\hline 46 & Yes & $4+$ & \\
\hline 47 & No & normal & \\
\hline 48 & Yes & $5+$ & \\
\hline 49 & Yes & $25+$ & \\
\hline 50 & Yes & $5+$ & \\
\hline 51 & No & 3 & \\
\hline 52 & No & 3 & \\
\hline 53 & Yes & $7+$ & \\
\hline 54 & Yes & $7+$ & \\
\hline 55 & Yes & $7+$ & $5-6$ \\
\hline 56 & Yes & $12+$ & \\
\hline 57 & No & normal & \\
\hline 58 & Yes & $12+$ & \\
\hline 59 & Yes & $6+$ & \\
\hline 60 & No & normal & \\
\hline 61 & Yes & $8+$ & \\
\hline 62 & Yes & $8+$ & \\
\hline 63 & No & normal & \\
\hline 64 & Yes & $7+$ & \\
\hline 65 & Yes & $9+$ & \\
\hline
\end{tabular}

Abbreviations: FISH fluorescent in situ hybridization, HER2 human epidermal growth factor receptor-2, UPD uniparental disomy.

In addition, SNP arrays provide information about polyploidy, which is generally considered to reflect genomic instability and may promote cell transformation [39]. Increased HER2 gene copy number caused by chromosome 17 polysomy has been reported to be a contributing factor in HER2 overexpression in otherwise unamplified invasive breast carcinomas [40]. It was proposed that cases carrying chromosome 17 polysomy should be further evaluated for HER2 protein overexpression by IHC. Other studies, however, have failed to demonstrate a correlation between chromosome 17 polysomy and expression of HER2 protein $[28,41,42]$.

We observed that more than two thirds of the tumors studied here were polyploidy, including 18 polyploid samples determined as IHC 0 or IHC $1+$. Although our tumor material was selected to contain a large number of IHC 2+ tumors, the data are in contrast to recent studies reporting chromosome 17 polysomy (defined as 3 or more copies of the chromosome 17 centromere) with a frequency of $0-46 \%[27,28,41,43-53]$. Comparative genomic hybridization (CGH) array studies in particular have concluded that chromosome 17 polysomy in breast cancer is rare and only occurs in about $5 \%$ of 
tumors [27,52]. CGH array may, however, not be optimal for detection of polyploidy/chromosome 17 polysomy because the data analysis is based on the Hidden Markov Model which may fail to uncover polyploidy. Further studies are required to clarify the significance of chromosome 17 polysomy in breast cancer patients.

Other techniques of HER2 testing besides IHC and FISH analysis have previously been suggested, including chromogenic in situ hybridisation (CISH) [54,55], silver enhanced in situ hybridisation (SISH) [56], Q-RT-PCR [57] and multiplex ligation-dependent probe amplification (MLPA) [58]. Our study shows that SNP array should be included as a HER2 testing method as well. Moreover, recent changes in clinical protocols require examination of deletions and amplification of the $T O P 2 A$ gene as well. In the near term future we expect a rising demand in the examination of several gene alterations from the same tumor. In this regard SNP chip array will be a time and money saving procedure investigating these genomic alterations, since it includes the simultaneous examination of all chromosomes. Moreover, SNP arrays can be analyzed within three working days, so results can be provided to the clinical department in the same time frame as IHC/FISH data. One limitation for the clinical use of SNP arrays is the use of fresh-frozen tumor tissue, since fresh-frozen tumor samples are not available for routine diagnostics in many countries. However protocols for SNP arrays using formalin-fixed paraffin-embedded tissue have recently been described [59], suggesting a broader application of SNP array analysis in a clinical setting in the near future.

\section{Conclusion}

In summary, we conclude that copy number analysis by means of SNP arrays offers a number of advantages and improvements that may warrant their use in HER2 diagnostics. Most importantly, array-based analysis is accurate and identifies more breast tumors for targeted treatment. The analysis is fast and generates highly reproducible and quantitative data. Moreover, it provides a global view that allows rapid evaluation of multiple regions of interest. Future studies are needed to evaluate response of Trastuzumab in patients with HER2 positive tumors identified by SNP array analysis. This could be done retrospective or in a randomised control trial.

\section{Additional files}

Additional file 1: Table S1. Pathological data of 65 breast tumors. The breast tumors consisted of ductal carcinomas, lobular carcinomas, mixed ductal/lobular carcinomas, or mucinous carcinomas. The tumors were graded according to the following: Grading 3-5= Grade 1, 6-7 = Grade 2, $8-9=$ Grade 3 . The mucinous tumors were not graded. ER and PgR were regarded as negative (0) when staining is less than 10\%. One tumor (29) was of unknown ER and PgR status. Abbreviations: DC, ductal carcinoma;
Diam, diameter; ER, estrogen receptor; LC, lobular cancinoma; MC: mucinous carcinoma; PgR, progesterone receptor.

Additional file 2: Figure S1. Copy number variations observed in the 65 breast tumors showing the frequencies of genomic copy number gains and losses plotted according to their genomic localization. Blue lines correspond to allelic losses and red lines depict gains. Data from SNP $500 \mathrm{~K}$ and SNP 6.0 are displayed separately. Sixty percent of the tumors have amplification of chromosome 1q. A third of the samples have amplification of chromosome $5 p$, while about half of the tumors have loss of chromosome $8 p$ from p.12 and beyond - frequently in combination with amplification of chromosome $8 \mathrm{q}$, identified in about $60 \%$ of the tumors. Almost a third of the tumors show a high copy number amplification of the end of chromosome 8 from p.11.21 into the beginning of p.12 and approximately half of the tumors have loss of chromosome 11q from q.14.1 to the telomere. Finally, amplification of chromosome $16 p$ is seen in almost half of the tumors and often in combination with loss of chromosome 16q, while loss of chromosome $17 p$ is seen in about $40 \%$ of the tumors.

Additional file 3: Figure S2. Detection of polyploidy. (A) SNP and copy number data across chromosome 3 from tumor sample 45. The top panel displays the copy number probe intensity calls and the calculated copy number segments (in color). The lower panel displays the calculated SNP allele ratios of chromosome 3 . The calculated segments have varying intensity values. The fragment with the lowest intensity value represents at least 3 copies because it exhibits allelic imbalance but still displays SNP heterozygosity (red arrows). Each fragment can be assigned an increasing copy number intensity, revealing that the predicted 'copy number 2' intensity corresponds to between 5 and 6 copies of DNA. (B) Subsequent examination of chromosome 17 shows that HER2 must be present in at least 7 copies. This sample also displays amplification of the centromere region (q-arm side) to the same extent as HER2, explaining why the FISH HER2/CEP17 ratio is 1.66. The vertical red line indicates the position of the centromere and HER2. (C) Representative image of a 3D-rendered model of a confocal image stack of a section from tumor sample 45 hybridized with HER2 (red) and CEP17 (green) probes. The image extends 6 um down into the $z$-axis, corresponding to $\sim 60-70 \%$ of the nucleus diameter.

\section{Competing interests}

The authors declare that they have no competing interests.

\section{Authors' contributions}

The study was conceived and designed by FCN, VTW and TVOH. TVOH, JV, SSB, HHR, VTW and FCN participated in the collection and assembly of data and were involved in data analysis and interpretation. All authors were involved in the writing of the manuscript and approval of the final version of the manuscript.

\section{Acknowledgements}

Vibeke Trandbohus, Elisabeth Schiefloe, and Susanne Smed are thanked for excellent technical assistance. The study is supported by a grant from the NEYE Foundation.

\section{Author details}

${ }^{1}$ Center for Genomic Medicine, Copenhagen University Hospital, Blegdamsvej 9 , DK-2100 Copenhagen, Denmark. ${ }^{2}$ Department of Pathology, Rigshospitalet, Copenhagen University Hospital, Blegdamsvej 9, DK-2100 Copenhagen, Denmark.

Received: 18 December 2013 Accepted: 23 January 2015 Published online: 06 February 2015

\section{References}

1. Ferlay J, Autier P, Boniol M, Heanue M, Colombet M, Boyle P. Estimates of the cancer incidence and mortality in Europe in 2006. Ann Oncol. 2007;18(3):581-92.

2. Owens MA, Horten BC, Da Silva MM. HER2 amplification ratios by fluorescence in situ hybridization and correlation with immunohistochemistry in a cohort of 6556 breast cancer tissues. Clin Breast Cancer. 2004;5(1):63-9. 
3. Slamon DJ, Clark GM, Wong SG, Levin WJ, Ullrich A, McGuire WL. Human breast cancer: correlation of relapse and survival with amplification of the HER-2/neu oncogene. Science. 1987;235(4785):177-82.

4. Hynes NE, MacDonald G. ErbB receptors and signaling pathways in cancer. Curr Opin Cell Biol. 2009;21(2):177-84.

5. Burstein HJ. The distinctive nature of HER2-positive breast cancers. N Engl J Med. 2005;353(16):1652-4.

6. Menard S, Fortis S, Castiglioni F, Agresti R, Balsari A. HER2 as a prognostic factor in breast cancer. Oncology. 2001;61 Suppl 2:67-72.

7. Mass RD, Press MF, Anderson S, Cobleigh MA, Vogel CL, Dybdal N, et al. Evaluation of clinical outcomes according to HER2 detection by fluorescence in situ hybridization in women with metastatic breast cancer treated with trastuzumab. Clin Breast Cancer. 2005;6(3):240-6.

8. Piccart-Gebhart MJ, Procter M, Leyland-Jones B, Goldhirsch A, Untch M, Smith I, et al. Trastuzumab after adjuvant chemotherapy in HER2-positive breast cancer. N Engl J Med. 2005;353(16):1659-72.

9. Robert N, Leyland-Jones B, Asmar L, Belt R, llegbodu D, Loesch D, et al. Randomized phase III study of trastuzumab, paclitaxel, and carboplatin compared with trastuzumab and paclitaxel in women with HER-2 overexpressing metastatic breast cancer. J Clin Oncol. 2006;24(18):2786-92.

10. Romond EH, Perez EA, Bryant J, Suman VJ, Geyer Jr CE, Davidson NE, et al. Trastuzumab plus adjuvant chemotherapy for operable HER2-positive breast cancer. N Engl J Med. 2005;353(16):1673-84.

11. Vogel CL, Cobleigh MA, Tripathy D, Gutheil JC, Harris LN, Fehrenbacher L, et al. Efficacy and safety of trastuzumab as a single agent in first-line treatment of HER2-overexpressing metastatic breast cancer. J Clin Oncol. 2002;20(3):719-26.

12. Bartlett JM, Going JJ, Mallon EA, Watters AD, Reeves JR, Stanton P, et al. Evaluating HER2 amplification and overexpression in breast cancer. J Pathol. 2001;195(4):422-8.

13. Dowsett M, Bartlett J, Ellis IO, Salter J, Hills M, Mallon E, et al. Correlation between immunohistochemistry (HercepTest) and fluorescence in situ hybridization (FISH) for HER-2 in 426 breast carcinomas from 37 centres. J Pathol. 2003;199(4):418-23.

14. Lebeau A, Deimling D, Kaltz C, Sendelhofert A, Iff A, Luthardt B, et al. Her-2/neu analysis in archival tissue samples of human breast cancer: comparison of immunohistochemistry and fluorescence in situ hybridization. J Clin Oncol. 2001;19(2):354-63.

15. Pauletti G, Dandekar S, Rong H, Ramos L, Peng H, Seshadri R, et al. Assessment of methods for tissue-based detection of the HER-2/neu alteration in human breast cancer: a direct comparison of fluorescence in situ hybridization and immunohistochemistry. J Clin Oncol. 2000;18(21):3651-64.

16. Perez EA, Suman VJ, Davidson NE, Martino S, Kaufman PA, Lingle WL, et al. HER2 testing by local, central, and reference laboratories in specimens from the North Central Cancer Treatment Group N9831 intergroup adjuvant trial. J Clin Oncol. 2006;24(19):3032-8.

17. Press MF, Sauter G, Bernstein L, Villalobos IE, Mirlacher M, Zhou JY, et al. Diagnostic evaluation of HER-2 as a molecular target: an assessment of accuracy and reproducibility of laboratory testing in large, prospective, randomized clinical trials. Clin Cancer Res. 2005;11(18):6598-607.

18. Press MF, Slamon DJ, Flom KJ, Park J, Zhou JY, Bernstein L. Evaluation of HER-2/neu gene amplification and overexpression: comparison of frequently used assay methods in a molecularly characterized cohort of breast cancer specimens. J Clin Oncol. 2002;20(14):3095-105.

19. Yaziji H, Goldstein LC, Barry TS, Werling R, Hwang H, Ellis GK, et al. HER-2 testing in breast cancer using parallel tissue-based methods. JAMA. 2004;291(16):1972-7.

20. Wolff AC, Hammond ME, Schwartz JN, Hagerty KL, Allred DC, Cote RJ, et al. American Society of Clinical Oncology/College of American Pathologists guideline recommendations for human epidermal growth factor receptor 2 testing in breast cancer. J Clin Oncol. 2007;25(1):118-45.

21. Bartlett JM, Ibrahim M, Jasani B, Morgan JM, Ellis I, Kay E, et al. External quality assurance of HER2 FISH and ISH testing: three years of the UK national external quality assurance scheme. Am J Clin Pathol. 2009;131(1):106-11.

22. Bartlett JM, Ibrahim M, Jasani B, Morgan JM, Ellis I, Kay E, et al. External quality assurance of HER2 fluorescence in situ hybridisation testing: results of a UK NEQAS pilot scheme. J Clin Pathol. 2007:60(7):816-9.

23. Chen $T, X u T$, Li Y, Liang $C$, Chen J, Lu Y, et al. Risk of cardiac dysfunction with trastuzumab in breast cancer patients: a meta-analysis. Cancer Treat Rev. 2011;37(4):312-20

24. Esteva FJ, Valero V, Booser D, Guerra LT, Murray JL, Pusztai $L$, et al. Phase II study of weekly docetaxel and trastuzumab for patients with HER-2overexpressing metastatic breast cancer. J Clin Oncol. 2002;20(7):1800-8.
25. Slamon DJ, Leyland-Jones B, Shak S, Fuchs H, Paton V, Bajamonde A, et al. Use of chemotherapy plus a monoclonal antibody against HER2 for metastatic breast cancer that overexpresses HER2. N Engl J Med. 2001;344(11):783-92.

26. Paik S, Kim C, Wolmark N. HER2 status and benefit from adjuvant trastuzumab in breast cancer. N Engl J Med. 2008;358(13):1409-11.

27. Marchio C, Lambros MB, Gugliotta P, Di Cantogno LV, Botta C, Pasini B, et al. Does chromosome 17 centromere copy number predict polysomy in breast cancer? A fluorescence in situ hybridization and microarray-based CGH analysis. J Pathol. 2009;219(1):16-24.

28. Vanden Bempt I, Van Loo P, Drijkoningen M, Neven P, Smeets A, Christiaens $M R$, et al. Polysomy 17 in breast cancer: clinicopathologic significance and impact on HER-2 testing. J Clin Oncol. 2008;26(30):4869-74.

29. Chin K, DeVries S, Fridlyand J, Spellman PT, Roydasgupta R, Kuo WL, et al. Genomic and transcriptional aberrations linked to breast cancer pathophysiologies. Cancer Cell. 2006;10(6):529-41.

30. Jonsson G, Staaf J, Vallon-Christersson J, Ringner M, Holm K, Hegardt C, et al. Genomic subtypes of breast cancer identified by array-comparative genomic hybridization display distinct molecular and clinical characteristics. Breast Cancer Res. 2010;12(3):R42.

31. Sauter G, Lee J, Bartlett JM, Slamon DJ, Press MF. Guidelines for human epidermal growth factor receptor 2 testing: biologic and methodologic considerations. J Clin Oncol. 2009;27(8):1323-33.

32. Ross JS. Saving lives with accurate HER2 testing. Am J Clin Pathol. 2010;134(2):183-4.

33. Schmidt C. How do you tell whether a breast cancer is HER2 positive? Ongoing studies keep debate in high gear. J Natl Cancer Inst. 2011;103(2):87-9.

34. de Leeuw N, Hehir-Kwa JY, Simons A, Geurts van Kessel A, Smeets DF, Faas $\mathrm{BH}$, et al. SNP array analysis in constitutional and cancer genome diagnosticscopy number variants, genotyping and quality control. Cytogenet Genome Res. 2011;135(3-4):212-21.

35. Zhang F, Gu W, Hurles ME, Lupski JR. Copy number variation in human health, disease, and evolution. Annu Rev Genomics Hum Genet. 2009;10:451-81.

36. Kauraniemi P, Barlund M, Monni O, Kallioniemi A. New amplified and highly expressed genes discovered in the ERBB2 amplicon in breast cancer by CDNA microarrays. Cancer Res. 2001;61(22):8235-40.

37. Kauraniemi P, Kuukasjarvi T, Sauter G, Kallioniemi A. Amplification of a 280kilobase core region at the ERBB2 locus leads to activation of two hypothetical proteins in breast cancer. Am J Pathol. 2003;163(5):1979-84.

38. Staaf J, Lindgren D, Vallon-Christersson J, Isaksson A, Goransson H, Juliusson $\mathrm{G}$, et al. Segmentation-based detection of allelic imbalance and loss-ofheterozygosity in cancer cells using whole genome SNP arrays. Genome Biol. 2008:9(9):R136.

39. Storchova Z, Kuffer C. The consequences of tetraploidy and aneuploidy. J Cell Sci. 2008;121(Pt 23):3859-66.

40. Shah SS, Ketterling RP, Goetz MP, Ingle JN, Reynolds CA, Perez EA, et al. Impact of American Society of Clinical Oncology/College of American Pathologists guideline recommendations on HER2 interpretation in breast cancer. Hum Pathol. 2009;41(1):103-6.

41. Downey L, Livingston RB, Koehler M, Arbushites M, Williams L, Santiago A, et al. Chromosome 17 polysomy without human epidermal growth factor receptor 2 amplification does not predict response to lapatinib plus paclitaxel compared with paclitaxel in metastatic breast cancer. Clin Cancer Res. 2010;16(4):1281-8.

42. Downs-Kelly E, Yoder BJ, Stoler M, Tubbs RR, Skacel M, Grogan T, et al. The influence of polysomy 17 on HER2 gene and protein expression in adenocarcinoma of the breast: a fluorescent in situ hybridization, immunohistochemical, and isotopic mRNA in situ hybridization study. Am J Surg Pathol. 2005;29(9):1221-7.

43. Baehner FL, Achacoso N, Maddala T, Shak S, Quesenberry Jr CP, Goldstein LC, et al. Human epidermal growth factor receptor 2 assessment in a case-control study: comparison of fluorescence in situ hybridization and quantitative reverse transcription polymerase chain reaction performed by central laboratories. J Clin Oncol. 2010;28(28):4300-6.

44. Brunelli M, Manfrin E, Martignoni G, Miller K, Remo A, Reghellin D, et al. Genotypic intratumoral heterogeneity in breast carcinoma with HER2/neu amplification: evaluation according to ASCO/CAP criteria. Am J Clin Pathol. 2009;131(5):678-82.

45. Chibon F, de Mascarel I, Sierankowski G, Brouste V, Bonnefoi H, Debled M, et al. Prediction of HER2 gene status in Her2 2+ invasive breast cancer: a study of 108 cases comparing ASCO/CAP and FDA recommendations. Mod Pathol. 2009;22(3):403-9. 
46. Hyun CL, Lee HE, Kim KS, Kim SW, Kim JH, Choe G, et al. The effect of chromosome 17 polysomy on HER-2/neu status in breast cancer. J Clin Pathol. 2008:61(3):317-21

47. Krishnamurti U, Hammers JL, Atem FD, Storto PD, Silverman JF. Poor prognostic significance of unamplified chromosome 17 polysomy in invasive breast carcinoma. Mod Pathol. 2009;22(8):1044-8.

48. Ma Y, Lespagnard L, Durbecq V, Paesmans M, Desmedt C, Gomez-Galdon $M$, et al. Polysomy 17 in HER-2/neu status elaboration in breast cancer: effect on daily practice. Clin Cancer Res. 2005;11(12):4393-9.

49. Moelans CB, de Weger RA, van Diest PJ. Absence of chromosome 17 polysomy in breast cancer: analysis by CEP17 chromogenic in situ hybridization and multiplex ligation-dependent probe amplification. Breast Cancer Res Treat. 2010;120(1):1-7.

50. Torrisi R, Rotmensz N, Bagnardi V, Viale G, Curto BD, Dell'orto P, et al. HER2 status in early breast cancer: relevance of cell staining patterns, gene amplification and polysomy 17. Eur J Cancer. 2007;43(16):2339-44.

51. Yaziji H, Gown AM. Accuracy and precision in HER2/neu testing in breast cancer: are we there yet? Hum Pathol. 2004;35(2):143-6.

52. Yeh IT, Martin MA, Robetorye RS, Bolla AR, McCaskill C, Shah RK, et al. Clinical validation of an array CGH test for HER2 status in breast cancer reveals that polysomy 17 is a rare event. Mod Pathol. 2009;22(9):1169-75.

53. Zhu X, Lu Y, Lu H, Yang W, Tu X, Cai X, et al. Genetic alterations and protein expression of HER2 and chromosome 17 polysomy in breast cancer. Hum Pathol. 2011:42(10):1499-504.

54. Di Palma S, Collins N, Bilous M, Sapino A, Mottolese M, Kapranos N, et al. A quality assurance exercise to evaluate the accuracy and reproducibility of chromogenic in situ hybridisation for HER2 analysis in breast cancer. J Clin Pathol. 2008:61(6):757-60

55. Pothos A, Plastira K, Plastiras A, Vlachodimitropoulos D, Goutas N, Angelopoulou R. Comparison of chromogenic in situ hybridisation with fluorescence in situ hybridisation and immunohistochemistry for the assessment of her-2/neu oncogene in archival material of breast carcinoma. Acta Histochem Cytochem. 2008;41(3):59-64.

56. Dietel M, Ellis IO, Hofler H, Kreipe H, Moch H, Dankof A, et al. Comparison of automated silver enhanced in situ hybridisation (SISH) and fluorescence ISH (FISH) for the validation of HER2 gene status in breast carcinoma according to the guidelines of the American Society of Clinical Oncology and the College of American Pathologists. Virchows Arch. 2007;451(1):19-25.

57. Barberis M, Pellegrini C, Cannone M, Arizzi C, Coggi G, Bosari S. Quantitative PCR and HER2 testing in breast cancer: a technical and cost-effectiveness analysis. Am J Clin Pathol. 2008;129(4):563-70.

58. Moerland $E$, van Hezik RL, van der Aa TC, van Beek MW, van den Brule AJ. Detection of HER2 amplification in breast carcinomas: comparison of Multiplex Ligation-dependent Probe Amplification (MLPA) and Fluorescence In Situ Hybridization (FISH) combined with automated spot counting. Cell Oncol. 2006;28(4):151-9.

59. Yu YP, Michalopoulos A, Ding Y, Tseng G, Luo JH. High fidelity copy number analysis of formalin-fixed and paraffin-embedded tissues using Affymetrix Cytoscan HD chip. PLoS One. 2014;9(4):e92820

\section{Submit your next manuscript to BioMed Central and take full advantage of:}

- Convenient online submission

- Thorough peer review

- No space constraints or color figure charges

- Immediate publication on acceptance

- Inclusion in PubMed, CAS, Scopus and Google Scholar

- Research which is freely available for redistribution

Submit your manuscript at www.biomedcentral.com/submit 